\title{
Article \\ Early Warning of Resistance to Bt Toxin Vip3Aa in Helicoverpa zea
}

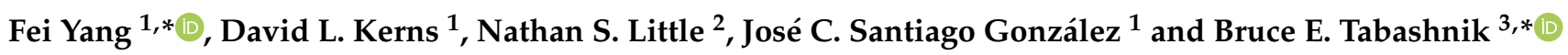 \\ 1 Department of Entomology, Texas A\&M University, College Station, TX 77843, USA; \\ dlkerns@tamu.edu (D.L.K.); josec.santiago@tamu.edu (J.C.S.G.) \\ 2 USDA Agricultural Research Service, Stoneville, MS 38776, USA; nathan.little@usda.gov \\ 3 Department of Entomology, University of Arizona, Tucson, AZ 85721, USA \\ * Correspondence: fyang@tamu.edu (F.Y.); brucet@cals.arizona.edu (B.E.T.)
}

check for updates

Citation: Yang, F.; Kerns, D.L.; Little, N.S.; Santiago González, J.C.; Tabashnik, B.E. Early Warning of Resistance to Bt Toxin Vip3Aa in Helicoverpa zea. Toxins 2021, 13, 618. https://doi.org/10.3390/toxins13090618

Received: 24 June 2021

Accepted: 27 August 2021

Published: 2 September 2021

Publisher's Note: MDPI stays neutral with regard to jurisdictional claims in published maps and institutional affiliations.

Copyright: (c) 2021 by the authors. Licensee MDPI, Basel, Switzerland. This article is an open access article distributed under the terms and conditions of the Creative Commons Attribution (CC BY) license (https:/ / creativecommons.org/licenses/by/ $4.0 /)$.

\begin{abstract}
Evolution of resistance by pests can reduce the benefits of crops genetically engineered to produce insecticidal proteins from Bacillus thuringiensis (Bt). Because of the widespread resistance of Helicoverpa zea to crystalline (Cry) Bt toxins in the United States, the vegetative insecticidal protein Vip3Aa is the only Bt toxin produced by Bt corn and cotton that remains effective against some populations of this polyphagous lepidopteran pest. Here we evaluated H. zea resistance to Vip3Aa using diet bioassays to test 42,218 larvae from three lab strains and 71 strains derived from the field during 2016 to 2020 in Arkansas, Louisiana, Mississippi, Tennessee, and Texas. Relative to the least susceptible of the three lab strains tested (BZ), susceptibility to Vip3Aa of the field-derived strains decreased significantly from 2016 to 2020. Relative to another lab strain (TM), 7 of 16 strains derived from the field in 2019 were significantly resistant to Vip3Aa, with up to 13-fold resistance. Susceptibility to Vip3Aa was significantly lower for strains derived from Vip3Aa plants than nonVip3Aa plants, providing direct evidence of resistance evolving in response to selection by Vip3Aa plants in the field. Together with previously reported data, the results here convey an early warning of field-evolved resistance to Vip3Aa in $H$. zea that supports calls for urgent action to preserve the efficacy of this toxin.
\end{abstract}

Keywords: Bacillus thuringiensis; resistance monitoring; Vip3Aa; sustainability; genetically engineered crop; corn; cotton

Key Contribution: We report evidence that some populations of Helicoverpa zea in the southern United States are beginning to evolve resistance to Bt toxin Vip3Aa. Because Vip3Aa is the only Bt toxin produced by transgenic corn and cotton that remains effective against some populations of this pest, action is needed now to preserve its efficacy.

\section{Introduction}

Transgenic crops producing insecticidal proteins from Bacillus thuringiensis (Bt) can provide safe and effective control of some key pests [1-4]. In 2019, farmers planted such Bt crops on 109 million hectares in 27 countries [5]. However, the benefits of Bt crops are diminished when pests adapt to Bt toxins [6-10]. In this context, field-evolved resistance is defined as a genetically based decrease in susceptibility of an insect population to a Bt toxin caused by selection in the field [7]. Field-evolved resistance has two categories: practical resistance and early warning of resistance [6]. Practical resistance is field-evolved resistance that decreases the efficacy of the Bt crop in the field and has practical consequences for pest control [8]. An additional criterion for practical resistance is that more than $50 \%$ of individuals in a population are resistant [8]. Early warning of resistance includes all cases of field-evolved resistance that do not meet the additional criteria for practical resistance [6]. For both categories of field-evolved resistance, at least one field population of the pest must meet the relevant criteria. 
Some populations of at least nine major lepidopteran and coleopteran pests have evolved practical resistance to Bt crystalline (Cry) toxins produced by transgenic crops [6,9,10], including Helicoverpa zea (corn earworm and bollworm), one of the most damaging crop pests in the United States $[3,11]$. Throughout much of the United States where this polyphagous lepidopteran is an important pest, it has evolved practical resistance to the Cry toxins produced by Bt corn and cotton, including Cry1Ab, Cry1Ac, Cry1A.105, Cry1Fa, and Cry2Ab [12-22]. Driven in part by this resistance, farmers have planted Bt corn and cotton that produce the Bt vegetative insecticidal protein Vip3Aa in addition to various Cry proteins $[15,23]$.

In the United States, Vip3Aa-producing corn and cotton were first registered in 2008 and 2009, respectively [24], but were not widely adopted until recently (Figure 1) [25,26]. Vip3 proteins are toxic to some lepidopteran larvae and have striking structural homology to Cry toxins, despite sharing no primary sequence similarity [27]. Like Cry toxins, Vip3 toxins are thought to kill insects by binding to specific receptors in the midgut $[27,28]$. Because Vip3 and Cry toxins do not bind to the same midgut receptors, strong crossresistance between them is unlikely [29]. Indeed, analysis of 48 paired observations in 34 strains of eight species of lepidopteran pests revealed weak cross-resistance between Cry1 and Vip3 toxins and no cross-resistance between Cry2 and Vip3 toxins [30].
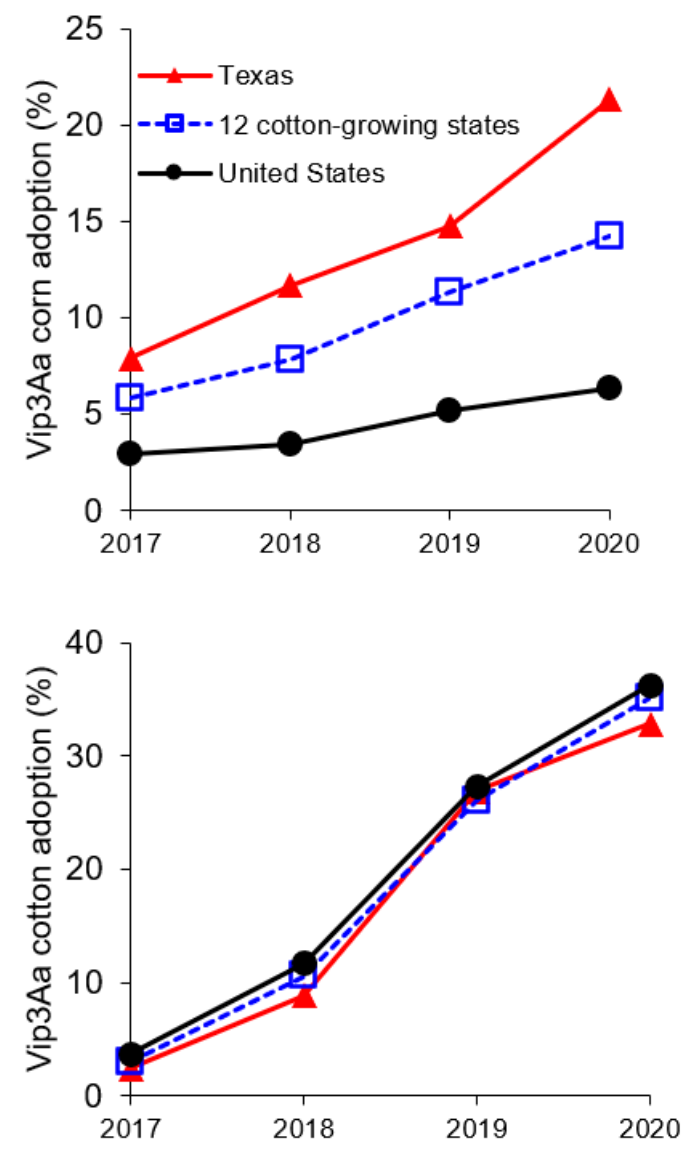

Figure 1. Percentage of corn or cotton hectares planted with corn or cotton producing Vip3Aa. ABSTC provided the data for Vip3Aa seed sales for 12 cotton-growing states (including Texas) and for the entire United States (see Supplementary Methods and Tables S1-S6 for details).

In two strains of $H$. zea selected in the lab for $>50$-fold resistance to Cry $1 \mathrm{Ac}$, the concentration of Vip3Aa killing 50\% of larvae $\left(\mathrm{LC}_{50}\right)$ did not increase in one strain [31]. In the other strain, however, the $\mathrm{LC}_{50}$ of Vip3Aa increased by 1.6-fold, revealing statistically significant but weak cross-resistance [32]. Because of the widespread practical resistance of 
H. zea to Cry toxins, Vip3Aa is the only Bt toxin in transgenic corn and cotton that remains effective against some populations of this pest in the United States [22].

Despite no strong cross-resistance between Cry toxins and Vip3Aa and the initial high efficacy of Vip3Aa against H. zea [33,34], some previously reported evidence suggests this pest has begun to evolve resistance to Vip3Aa in the southern United States [18-20,22,35]. For example, in a 2018 field trial at the Texas A\&M University (TAMU) field laboratory in Snook, Texas, H. zea larvae damaged $67.5 \%$ of corn producing Cry1Ab + Cry1Fa + Vip3Aa [19]. Also, for two strains of H. zea derived in 2018 from Bt corn at the site of the field trial, the $\mathrm{LC}_{50}$ of Vip3Aa was 21 times higher for the strain from corn containing Vip3Aa than for the strain from corn without Vip3Aa [19].

Here, to evaluate the status of $H$. zea resistance to Vip3Aa, we analyzed data from diet bioassays of three lab strains and 71 strains derived from the field from 2016 to 2020 in Arkansas, Louisiana, Mississippi, Tennessee, and Texas (AR, LA, MS, TN, and TX). Together with previously reported data, the results here provide strong evidence of an early warning of field-evolved resistance to Vip3Aa in H. zea.

\section{Results}

We conducted 80 diet bioassays testing 42,218 larvae from three long-term lab strains (BZ, SIMRU, and TM) and 71 strains derived in 2016 to 2020 from field populations in AR, LA, MS, TN, and TX (Tables 1-3, Supplementary Figure S1). Bioassays were performed at TAMU, except in 2016 when all seven were done at Louisiana State University (LSU, Table 1) and in 2019 when BZ, TM, and 16 field-derived strains were tested at TAMU, while BZ and 10 field-derived strains were tested at the Southern Insect Management Research Unit (SIMRU), USDA-ARS in Stoneville, MS (Table 3). The units for the $\mathrm{LC}_{50}$ values reported below are micrograms ( $\mu \mathrm{g}$ ) Vip3Aa per $\mathrm{cm}^{2}$ diet (with 95\% fiducial limits (FL)).

\subsection{Variation in Susceptibility to Vip3Aa among Lab Strains of H. zea}

Of the three lab strains tested, BZ was least susceptible to Vip3Aa. In two of the three direct comparisons between $\mathrm{BZ}$ and other lab strains tested at the same lab in the same year, BZ was significantly less susceptible than the other lab strains based on the conservative criterion of no overlap of the $95 \%$ FL of the $\mathrm{LC}_{50}$ values. In 2016, the $\mathrm{LC}_{50}$ of Vip3Aa was 2.8 times higher for BZ than for the SIMRU lab strain (Table 1); in 2019, it was 4.1 times higher for $\mathrm{BZ}$ than for the TM lab strain (Table 3). In the third direct comparison, the $\mathrm{LC}_{50}$ of Vip3Aa was 1.3 times higher for BZ than TM in 2018, which is not statistically significant (Table 2). In addition, the $\mathrm{LC}_{50}$ of Vip3Aa for BZ tested at SIMRU was 2.4 times higher than the $\mathrm{LC}_{50}$ of Vip3Aa for TM tested at TAMU (Table 3). No significant difference occurred in the $\mathrm{LC}_{50}$ of Vip3Aa for BZ between the tests in 2019 conducted at TAMU and the tests conducted at SIMRU.

We calculated the Vip3Aa resistance ratio (RR) as the $\mathrm{LC}_{50}$ of each strain divided by the $\mathrm{LC}_{50}$ of a lab strain tested in the same year in the same lab. We used the lab strain BZ as a standard for comparisons based on data throughout the study because it was the only lab strain tested in each year and at LSU, TAMU, and SIMRU. However, because BZ was the least susceptible of the three lab strains, comparisons with BZ tend to underestimate the magnitude and extent of resistance. Thus, to obtain results less likely to underestimate resistance, we also calculated RRs relative to the SIMRU lab strain in 2016 and relative to the TM lab strain for field-derived strains tested at TAMU in 2018 and 2019 (Tables 1-3). TM had nearly identical $\mathrm{LC}_{50}$ values in the two years it was tested: $0.16(0.11,0.25)$ in 2018 and $0.17(0.14,0.21)$ in 2019 (Tables 2 and 3). 
Table 1. Responses to Vip3Aa of H. zea larvae from two lab strains (BZ and SIMRU) and 17 strains derived from the field in 2016 and 2017.

\begin{tabular}{|c|c|c|c|c|c|c|c|c|}
\hline Host Plant ${ }^{a}$ & Bt Toxins in Host Plant ${ }^{a}$ & Field Site or Lab Strain Name & Pupae $^{\text {b }}$ & Larvae $^{c}$ & Slope \pm SE & $\mathrm{LC}_{50}(95 \% \mathrm{FL})^{\mathrm{d}}$ & RR vs. $\mathrm{BZ}^{\mathrm{e}}$ & RR vs. SIMRU \\
\hline \multicolumn{9}{|l|}{ 2016: LSU } \\
\hline Lab diet & None & BZ & / & 957 & $2.8 \pm 0.4$ & $0.97(0.85,1.11)$ & 1.0 & 2.8 \\
\hline Lab diet & None & SIMRU & / & 958 & $1.9 \pm 0.3$ & $0.35(0.22,0.56)$ & 0.4 & 1.0 \\
\hline BG2 cotton & Cry1Ac + Cry2Ab & Alexandria, LA & 37 & 945 & $1.8 \pm 0.2$ & $0.19(0.15,0.24)$ & 0.2 & 0.5 \\
\hline VT2P corn & Cry1A.105 + Cry2Ab & Leland, MS & 182 & 962 & $2.2 \pm 0.1$ & $0.14(0.12,0.16)$ & 0.1 & 0.4 \\
\hline Grain sorghum & None & Jackson, TN & 118 & 956 & $2.1 \pm 0.2$ & $0.16(0.12,0.21)$ & 0.2 & 0.5 \\
\hline BG2 cotton & Cry $1 \mathrm{Ac}+$ Cry2Ab & Jackson, TN & 92 & 943 & $1.8 \pm 0.2$ & $0.18(0.13,0.23)$ & 0.2 & 0.5 \\
\hline Lab diet & None & $\mathrm{BZ}$ & / & 895 & $2.8 \pm 0.3$ & $0.96(0.86,1.12)$ & 1.0 & / \\
\hline Grain sorghum & None & Rohwer, AR & 157 & 448 & $5.2 \pm 1.2$ & $1.25(1.00,1.57)$ & 1.3 & / \\
\hline Non-Bt cotton & None & Alexandria, LA & 131 & 448 & $2.4 \pm 0.2$ & $0.10(0.08,0.12)$ & 0.1 & / \\
\hline TwinLink cotton & Cry1Ab + Cry2Ae & Alexandria, LA & 107 & 448 & $1.7 \pm 0.3$ & $0.33(0.19,0.61)$ & 0.3 & / \\
\hline $\mathrm{BG} 2$ cotton & Cry $1 \mathrm{Ac}+$ Cry $2 \mathrm{Ab}$ & Jonesville, LA & 121 & 448 & $2.0 \pm 0.2$ & $0.15(0.12,0.18)$ & 0.2 & / \\
\hline Non-Bt corn & None & Winnsboro, LA & 186 & 895 & $2.1 \pm 0.4$ & $0.33(0.18,0.61)$ & 0.3 & / \\
\hline BG2 cotton & Cry1Ac + Cry2Ab & Benoit, MS & 69 & 448 & $1.3 \pm 0.2$ & $0.04(0.03,0.06)$ & 0.04 & / \\
\hline BG2 cotton & Cry1Ac + Cry2Ab & Silver City, MS & 75 & 448 & $3.2 \pm 0.3$ & $0.05(0.04,0.06)$ & 0.1 & / \\
\hline VT2P corn & Cry1A.105 + Cry2Ab & Stoneville, MS & 111 & 894 & $1.8 \pm 0.2$ & $0.06(0.04,0.07)$ & 0.1 & / \\
\hline Obsession corn & Cry1A.105 + Cry2Ab & Milan, TN & 135 & 448 & $2.3 \pm 0.2$ & $0.12(0.10,0.14)$ & 0.1 & / \\
\hline WS cotton & Cry1Ab + Cry1Fa & Snook, TX & 77 & 896 & $2.1 \pm 0.4$ & $0.03(0.02,0.04)$ & 0.03 & / \\
\hline TwinLink cotton & Cry $1 \mathrm{Ab}+$ Cry2Ae & Wharton, TX & 20 & 895 & $5.7 \pm 0.9$ & $0.82(0.73,0.90)$ & 0.9 & / \\
\hline
\end{tabular}

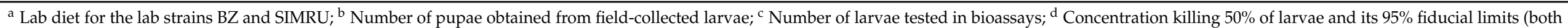
in $\mu \mathrm{g}$ Vip3Aa per $\mathrm{cm}^{2}$ diet); ${ }^{\mathrm{e}} \mathrm{LC}_{50}$ of strain divided by $\mathrm{LC}_{50}$ for $\mathrm{BZ}$ tested in the same year; ${ }^{\mathrm{f}} \mathrm{LC}_{50}$ of strain divided by $\mathrm{LC}_{50}$ for SIMRU, calculated only for strains tested in 2016 . 
Table 2. Responses to Vip3Aa of H. zea larvae from two lab strains (BZ and TM) and 23 strains derived from the field in 2018 (all tested at TAMU).

\begin{tabular}{|c|c|c|c|c|c|c|c|c|}
\hline Host Plant $^{a}$ & Bt Toxins in Host Plant ${ }^{a}$ & Field Site or Lab Strain Name & Pupae $^{b}$ & Larvae $^{c}$ & Slope \pm SE & $L^{2} C_{50}(95 \% \mathrm{FL})^{\mathrm{d}}$ & RR vs. BZ ${ }^{\mathrm{e}}$ & RR vs. $T M^{f}$ \\
\hline Lab diet & None & $\mathrm{BZ}$ & / & 448 & $1.5 \pm 0.1$ & $0.20(0.16,0.26)$ & 1.0 & 1.3 \\
\hline Lab diet & None & $\mathrm{TM}$ & / & 448 & $2.2 \pm 0.4$ & $0.16(0.11,0.25)$ & 0.8 & 1.0 \\
\hline Intrasect corn & Cry1Ab + Cry1F & Little Rock, AR & 130 & 448 & $2.1 \pm 0.2$ & $0.05(0.04,0.06)$ & 0.3 & 0.3 \\
\hline Non-Bt corn & None & Pine Bluff, AR & 280 & 448 & $3.1 \pm 0.3$ & $0.13(0.11,0.16)$ & 0.7 & 0.8 \\
\hline BG2 cotton & Cry1Ac + Cry2Ab & Alexandria, LA & 300 & 448 & $2.1 \pm 0.2$ & $0.05(0.04,0.06)$ & 0.3 & 0.3 \\
\hline WS3 cotton & Cry1Ac + Cry1Fa + Vip3Aa & Grant, LA & 240 & 448 & $2.7 \pm 0.4$ & $0.12(0.10,0.16)$ & 0.6 & 0.8 \\
\hline Crimson clover & None & Winnsboro, LA & 300 & 448 & $2.5 \pm 0.2$ & $0.06(0.05,0.07)$ & 0.3 & 0.4 \\
\hline Soybean & None & Indianola, MS & 120 & 448 & $2.5 \pm 0.4$ & $0.18(0.12,0.25)$ & 0.9 & 1.1 \\
\hline Crimson clover & None & Natchez, MS & 220 & 448 & $2.0 \pm 0.3$ & $0.19(0.12,0.31)$ & 1.0 & 1.2 \\
\hline Obsession corn & Cry1A.105 + Cry2Ab & Jackson, TN & 180 & 448 & $2.2 \pm 0.3$ & $0.21(0.15,0.31)$ & 1.1 & 1.3 \\
\hline BG2 cotton & Cry $1 A c+$ Cry $2 A b$ & Jackson, TN & 150 & 448 & $1.9 \pm 0.3$ & $0.01(0.01,0.02)$ & 0.1 & 0.1 \\
\hline Non-Bt corn & None & Amarillo, TX & 193 & 448 & $2.2 \pm 0.4$ & $0.15(0.13,0.18)$ & 0.8 & 0.9 \\
\hline VT3P corn & Cry1A.105 + Cry2Ab & Snook, TXg & 300 & 448 & $2.8 \pm 0.3$ & $0.04(0.03,0.05)$ & 0.2 & 0.3 \\
\hline WS cotton & Cry1Ac + Cry1Fa & Snook, TX & 200 & 448 & $3.3 \pm 1.0$ & $0.37(0.20,0.71)$ & 1.9 & 2.3 \\
\hline Leptra corn & Cry $1 \mathrm{Ab}+\mathrm{Cry} 1 \mathrm{Fa}+\mathrm{Vip} 3 \mathrm{Aa}$ & Snook, $\mathrm{TX}^{\mathrm{h}}$ & 100 & 448 & $4.9 \pm 1.0$ & $0.84(0.69,0.97)$ & $4.2 *$ & $5.3 *$ \\
\hline BG2 cotton & Cry1Ac + Cry2Ab & EI Campo, TX & 28 & 448 & $2.8 \pm 0.3$ & $0.05(0.04,0.06)$ & 0.3 & 0.3 \\
\hline Non-Bt corn & None & Lubbock, TX & 272 & 448 & $4.2 \pm 0.5$ & $0.17(0.15,0.20)$ & 0.9 & 1.1 \\
\hline VT2P corn & Cry1A.105 + Cry2Ab & Muleshoe, TX & 210 & 448 & $1.8 \pm 0.2$ & $0.03(0.02,0.04)$ & 0.2 & 0.2 \\
\hline Grain sorghum & None & Port Lavaca, TX & 138 & 448 & $2.8 \pm 0.3$ & $0.09(0.07,0.11)$ & 0.5 & 0.6 \\
\hline STX corn & Cry1A.105 + Cry1Fa + Cry2Ab & Thrall, TX & 87 & 448 & $2.1 \pm 0.2$ & $0.08(0.07,0.10)$ & 0.4 & 0.5 \\
\hline BG2 cotton & Cry1Ac + Cry2Ab & Wellington, $\mathrm{TX}$ & 108 & 448 & $2.5 \pm 0.3$ & $0.03(0.03,0.04)$ & 0.2 & 0.2 \\
\hline BG2 cotton & Cry1Ac + Cry2Ab & Wharton, TX & 70 & 448 & $2.9 \pm 0.6$ & $0.02(0.01,0.03)$ & 0.1 & 0.1 \\
\hline VT3P corn & Cry1A.105 + Cry $2 \mathrm{Ab}$ & Wall, TX & 103 & 448 & $2.3 \pm 0.3$ & $0.16(0.12,0.22)$ & 0.8 & 1.0 \\
\hline
\end{tabular}

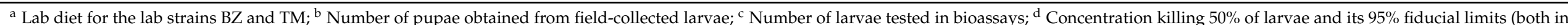

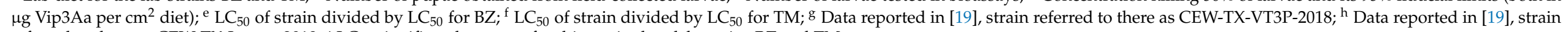
referred to there as CEW-TX-Leptra-2018; ${ }^{*} \mathrm{LC}_{50}$ significantly greater for this strain than lab strains BZ and TM. 
Table 3. Responses to Vip3Aa of H. zea larvae from two lab strains (BZ and TM) and 31 strains derived from the field in 2019 and 2020.

\begin{tabular}{|c|c|c|c|c|c|c|c|c|}
\hline Host Plant ${ }^{a}$ & Bt Toxins in Host Plant ${ }^{\text {a }}$ & Field Site or Lab Strain Name & Pupae $^{\text {b }}$ & Larvae $^{c}$ & Slope \pm SE & $\mathrm{LC}_{50}(95 \% \mathrm{FL})^{\mathrm{d}}$ & RR vs. BZ ${ }^{\mathrm{e}}$ & RR vs. TM ${ }^{f}$ \\
\hline \multicolumn{9}{|l|}{ 2019: TAMU } \\
\hline Lab diet & None & BZ & / & 448 & $3.7 \pm 0.5$ & $0.69(0.56,0.87)$ & 1.0 & $4.1^{*}$ \\
\hline Lab diet & None & $\mathrm{TM}^{\mathrm{g}}$ & / & 448 & $2.8 \pm 0.3$ & $0.17(0.14,0.21)$ & 0.2 & 1.0 \\
\hline VT2P corn & Cry1A.105 + Cry2Ab & Lafayette Co., AR & 120 & 448 & $2.8 \pm 0.3$ & $0.39(0.33,0.47)$ & 0.6 & $2.3 *$ \\
\hline VT2P corn & Cry1A.105 + Cry2Ab & Tillar, AR & 115 & 448 & $2.5 \pm 0.3$ & $0.15(0.13,0.19)$ & 0.2 & 0.9 \\
\hline VT2P corn & Cry1A.105 + Cry2Ab & Alexandria, LA & 278 & 448 & $2.2 \pm 0.2$ & $0.23(0.18,0.28)$ & 0.3 & 1.4 \\
\hline BG2 cotton & Cry1Ac + Cry2Ab & Alexandria, LA & 180 & 448 & $2.5 \pm 0.2$ & $0.24(0.20,0.29)$ & 0.3 & 1.4 \\
\hline VT2P corn & Cry1A.105 + Cry2Ab & Winnsboro, LA & 198 & 448 & $2.5 \pm 0.2$ & $0.14(0.12,0.17)$ & 0.2 & 0.8 \\
\hline Leptra corn & Cry1Ab + Cry1Fa + Vip3Aa & Stoneville, MS & 82 & 448 & $1.6 \pm 0.3$ & $2.21(1.27,4.44)$ & $3.2 *$ & 13.0 * \\
\hline VT2P corn & Cry1A.105 + Cry2Ab & Stoneville, MS & 105 & 448 & $2.9 \pm 0.3$ & $0.08(0.07,0.10)$ & 0.1 & 0.5 \\
\hline VT2P corn & Cry1A.105 + Cry2Ab & Starkville, MS & 285 & 448 & $2.8 \pm 0.3$ & $0.16(0.13,0.19)$ & 0.2 & 0.9 \\
\hline VT2P corn & Cry1A.105 + Cry2Ab & Jackson, TN & 210 & 448 & $2.5 \pm 0.3$ & $0.32(0.24,0.44)$ & 0.5 & $1.9^{*}$ \\
\hline VT2P corn & Cry1A.105 + Cry2Ab & Hillsboro, TX & 90 & 448 & $3.6 \pm 0.4$ & $0.30(0.25,0.35)$ & 0.4 & $1.8 *$ \\
\hline BG2 cotton & Cry1Ac + Cry2Ab & Jackson, TX & 100 & 448 & $3.0 \pm 1.3$ & $0.20(0.03,0.17)$ & 0.3 & 1.2 \\
\hline Non-Bt corn & None & Lubbock, TX & 172 & 448 & $2.9 \pm 0.3$ & $0.28(0.24,0.34)$ & 0.4 & $1.6^{*}$ \\
\hline BG2 cotton & Cry1Ac + Cry2Ab & Navasota, TX & 117 & 448 & $3.1 \pm 0.3$ & $0.08(0.07,0.10)$ & 0.1 & 0.5 \\
\hline Leptra corn & Cry1Ab + Cry1Fa + Vip3Aa & Snook, TX & 46 & 448 & $1.8 \pm 0.2$ & $0.66(0.49,0.89)$ & 1.0 & $3.9 *$ \\
\hline BG3 cotton & Cry1Ac + Cry2Ab + Vip3Aa & Snook, TX & 123 & 448 & $1.8 \pm 0.2$ & $0.50(0.40,0.63)$ & 0.7 & $2.9^{*}$ \\
\hline Non-Bt corn & None & Wharton, TX & 102 & 448 & $2.1 \pm 0.2$ & $0.24(0.19,0.29)$ & 0.3 & 1.4 \\
\hline \multicolumn{9}{|l|}{ 2019: SIMRU } \\
\hline Lab diet & None & BZ & / & 512 & $1.7 \pm 0.3$ & $0.41(0.26,0.68)$ & 1.0 & / \\
\hline Crimson clover & None & Grenada, MS & 242 & 512 & $2.6 \pm 0.3$ & $0.10(0.08,0.12)$ & 0.2 & / \\
\hline Crimson clover & None & Marks, MS & 177 & 512 & $1.5 \pm 0.2$ & $0.21(0.13,0.35)$ & 0.5 & / \\
\hline Non-Bt corn & None & Mound Bayou, MS & 451 & 512 & $2.4 \pm 0.3$ & $0.140 .11,0.19)$ & 0.3 & / \\
\hline Crimson clover & None & Olive Branch, MS & 400 & 384 & $2.4 \pm 0.4$ & $0.12(0.08,0.17)$ & 0.3 & / \\
\hline VT2P corn & Cry1A.105 + Cry2Ab & Rolling Fork, MS & 240 & 512 & $2.1 \pm 0.2$ & $0.16(0.12,0.21)$ & 0.4 & / \\
\hline Non-Bt corn & None & Stoneville, MS & 282 & 512 & $2.4 \pm 0.3$ & $0.32(0.24,0.44)$ & 0.8 & / \\
\hline TwinLink cotton & Cry1Ab + Cry2Ae & Stoneville, MS & 79 & 512 & $1.9 \pm 0.2$ & $0.06(0.04,0.10)$ & 0.2 & / \\
\hline Crimson clover & None & Warren County, MS & 201 & 512 & $1.6 \pm 0.2$ & $0.16(0.11,0.22)$ & 0.4 & / \\
\hline \multicolumn{9}{|l|}{ 2020: TAMU } \\
\hline Lab diet & None & $\mathrm{BZ}$ & / & 448 & $3.2 \pm 0.4$ & $0.11(0.09,0.13)$ & 1.0 & / \\
\hline VT2P corn & Cry1A.105 + Cry2Ab & Stoneville, MS & 186 & 448 & $3.9 \pm 0.5$ & $0.06(0.05,0.06)$ & 0.5 & / \\
\hline VT2P corn & Cry1A.105 + Cry2Ab & Pine Bluff, AR & 135 & 448 & $1.3 \pm 0.2$ & $0.05(0.03,0.08)$ & 0.5 & / \\
\hline VT2P corn & Cry1A.105 + Cry2Ab & Alexandria, LA & 93 & 448 & $2.6 \pm 0.5$ & $0.03(0.02,0.03)$ & 0.2 & / \\
\hline Non-Bt corn & None & Winnsboro, LA & 210 & 448 & $3.7 \pm 0.6$ & $0.04(0.03,0.04)$ & 0.3 & / \\
\hline VT2P corn & Cry1A.105 + Cry2Ab & Jackson, TN & 178 & 448 & $3.4 \pm 0.4$ & $0.10(0.09,0.12)$ & 0.9 & / \\
\hline
\end{tabular}

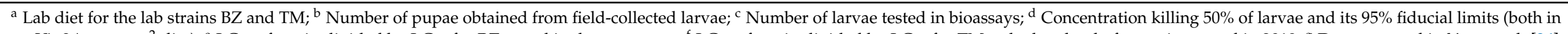

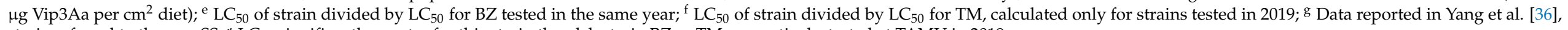
strain referred to there as SS; * $\mathrm{LC}_{50}$ significantly greater for this strain than lab strain BZ or TM, respectively, tested at TAMU in 2019. 


\subsection{Resistance to Vip3Aa in Field-Derived Strains of H. zea Relative to Lab Strains}

For the 71 field-derived strains, the Vip3Aa RR relative to BZ increased significantly from 2016 to 2020 (Figure 2). This genetically based decrease in susceptibility over time provides evidence of field-evolved resistance to Vip3Aa. Based on comparisons to BZ within each year, the $\mathrm{LC}_{50}$ values of Vip3Aa were significantly higher than BZ for 2 of the 71 field-derived strains: one established in 2018 from Snook, TX and the other in 2019 from Stoneville, MS (Tables 2 and 3). The RRs relative to BZ for these strains were 4.2 and 3.2, respectively. Both strains were started with larvae collected from corn producing Cry1Ab + Cry1Fa + Vip3Aa.

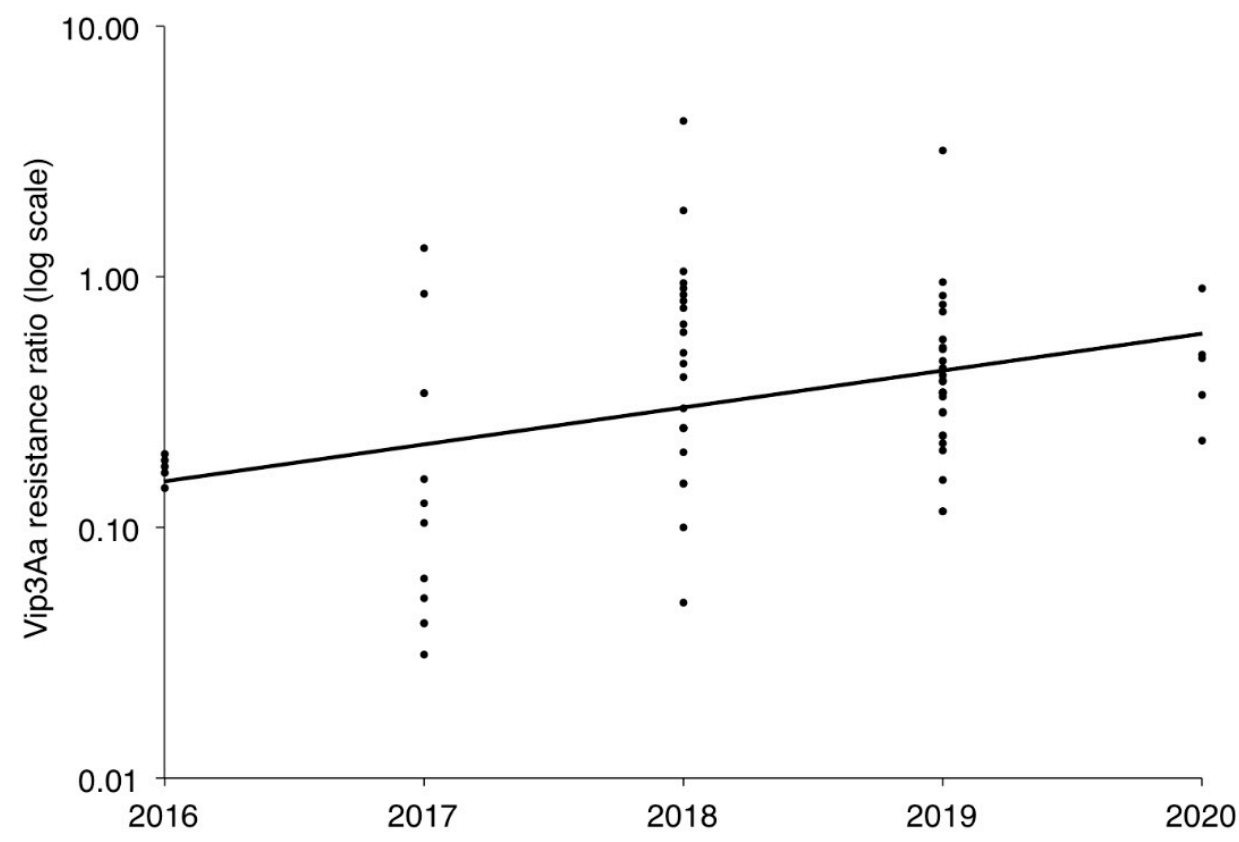

Figure 2. Increase from 2016 to 2020 in the Vip3Aa resistance ratio relative to the BZ lab strain for 71 field-derived strains of Helicoverpa zea. Linear regression: $\log (\mathrm{y})=0.14 \mathrm{X}-282 ; R^{2}=0.12 ; \mathrm{df}=69$; $p=0.003$.

For the 39 field-derived strains tested at TAMU in 2018 and 2019, the LC $_{50}$ values were significantly higher than the TM lab strain for 1 of the 23 strains started in 2018 and 7 of the 16 strains started in 2019 (Tables 2 and 3). The proportion of field-derived strains tested at TAMU with LC $_{50}$ values significantly higher than TM increased 10-fold from 2018 (0.043) to 2019 (0.44) (Fisher's exact test; $p=0.004$ ). The maximum RRs relative to TM were 5.3 in 2018 and 13.0 in 2019, which were recorded for the two strains described above derived from corn producing Cry1Ab + Cry1Fa + Vip3Aa (Tables 2 and 3).

We were able to establish five strains from $H$. zea collected in 2018 and 2019 on plants producing Vip3Aa, which reflects the substantial presence of the pest on these plants (mean: 118 pupae obtained per strain; range: 43 to 240; Tables 2 and 3). In addition to the two strains described above, we derived strains in 2018 from Grant, LA from cotton producing Cry1Ac + Cry1Fa + Vip3a; and in 2019 from Snook, TX from cotton producing Cry1Ac + Cry2Ab + Vip3Aa and corn producing Cry1Ab + Cry1Fa + Vip3Aa (Tables 2 and 3).

\subsection{Resistance to Vip3Aa in H. zea from Vip3Aa Plants Relative to Non-Vip3Aa Plants}

Providing direct evidence of evolution of resistance in response to selection imposed by exposure to Vip3Aa in the field, Vip3Aa RRs were higher for strains derived from Vip3Aa-producing plants than for comparable strains from plants that did not produce Vip3Aa. For the 39 field-derived strains tested at TAMU during 2018 and 2019, the Vip3Aa RRs relative to TM were 5.7-fold higher for the five strains from Vip3Aa plants (3.3) than for 
the 34 strains from non-Vip3Aa plants (0.6) ( $t$-test of log-transformed RRs; $t=3.8 ; \mathrm{df}=37$; $p=0.0005)$.

In addition, two of the five strains derived from Vip3Aa plants can be compared directly with strains derived from non-Vip3Aa plants from the same field site during the same season. Among the three strains established from Snook, TX in 2018, the LC $_{50}$ for the strain from Cry1 Ab + Cry1Fa + Vip3Aa corn was 21 times higher than for the strain from Cry1A.105 + Cry2Ab corn, as reported previously [19], and 2.3 times higher than for the strain from Cry1Ac + Cry1Fa cotton (Table 2). For the two strains established from Stonesville, MS in 2019, the $\mathrm{LC}_{50}$ for the strain from Cry1Ab + Cry1Fa + Vip3Aa corn was 28 times higher than for the strain from Cry1A.105 + Cry2Ab corn (Table 3).

In contrast with the results above for the 39 field-derived strains tested at TAMU during 2018 and 2019, no significant difference in Vip3Aa RRs relative to TM for these 39 strains occurred between the strains from Bt plants $(n=28)$ versus non-Bt plants $(n=11)$ (mean for Bt: 0.83 and non-Bt: 0.81; $t$-test of log-transformed RRs, $t=0.04, \mathrm{df}=37, p=0.97$ ). These results imply that selection for resistance to Vip3Aa was imposed specifically by Vip3Aa plants rather than by Bt plants generally, which is consistent with the lack of strong cross-resistance between Vip3Aa and Cry1 toxins or Cry2Ab [30].

\section{Discussion}

Several lines of evidence based on the diet bioassay results from this study support the conclusion that some $\mathrm{H}$. zea field populations evaluated here have begun to evolve resistance to Vip3Aa. First, the Vip3Aa RR relative to lab strain BZ increased significantly from 2016 to 2020 in a collective analysis of the 71 strains derived from field populations throughout the five-state region studied here. Second, BZ was the least susceptible of the three lab strains tested and statistically significant resistance to Vip3Aa relative to BZ occurred in one strain derived from the field in 2018 and another in 2019. Third, relative to the lab strain TM, 7 of the 16 strains that were derived from field in 2019 and tested at TAMU were resistant to Vip3Aa, with a maximum RR of 13. Fourth, the proportion of fieldderived strains tested at TAMU resistant to Vip3Aa relative to TM increased significantly from 0.043 in 2018 to 0.44 in 2019. Fifth, overall and in pairwise comparisons between strains established from the same field site and year, $\mathrm{LC}_{50}$ values of Vip3Aa were higher for strains derived from Vip3Aa plants than from non-Vip3Aa plants. This provides direct evidence of field-evolved resistance in response to selection by Vip3Aa in the field.

The response to selection noted above demonstrates substantial heritability of resistance to Vip3Aa in field populations. Such heritability is maximized at intermediate resistance allele frequencies and minimized at resistance allele frequencies close to either zero or one [37]. Based on an $\mathrm{F}_{2}$ screen of 114 families of $H$. zea derived from Snook, TX in 2019, the frequency of completely recessive resistance alleles that conferred over 500-fold resistance to Vip3Aa was estimated as 0.0065 (95\% confidence interval $=0.0014-0.0157)[36,38]$. Assuming Hardy-Weinberg equilibrium, the frequency of homozygous resistant individuals carrying such alleles in 2019 was 0.000042 (4.2 per 100,000). This frequency is expected to have essentially no effect on $\mathrm{LC}_{50}$ values in 2019. Moreover, because Vip3Aa plants accounted for considerably less than $100 \%$ of $H$. zea host plants in 2019 and 2020, we expect the frequency of these recessive resistance alleles was also too low to substantially affect $L_{50}$ values in 2020. For example, the expected frequency of individuals homozygous for these recessive resistance alleles in 2020 is $0.000060(6.0$ per 100,000) based on a population genetic model under the pessimistic assumptions that these alleles confer complete resistance of homozygotes to Vip3Aa plants, they carry no fitness cost on non-Vip3Aa plants, and refuges of non-Vip3Aa plants accounted for $10 \%$ of all $\mathrm{H}$. zea host plants (see Methods). Thus, we hypothesize that the resistance observed in the diet bioassays here was not caused primarily by the recessive resistance alleles isolated from the $\mathrm{F}_{2}$ screen, but rather by more common alleles with smaller effects that are probably not recessive.

It is useful to compare the results from the diet overlay bioassays conducted here with results from the four previous studies that used similar methods to assess responses of 
H. zea larvae to Vip3Aa [21,22,39,40]. Niu et al. [22] used diet overlay bioassays to compare the $\mathrm{LC}_{50}$ of Vip3Aa they measured for the BZ strain $\left(0.40 \mu \mathrm{g}\right.$ per $\mathrm{cm}^{2}$ diet, $95 \% \mathrm{FL}=0.30$, 0.51) versus 29 strains derived from the field in 2018 and 2019 from seven southern states (Arkansas, Florida, Georgia, Louisiana, Mississippi, North Carolina, and South Carolina). Based on no overlap with the $95 \% \mathrm{FL}$ of the $\mathrm{LC}_{50}$ of BZ, they reported the $\mathrm{LC}_{50}$ of Vip3Aa was significantly higher for $21 \%$ (6 of 29 ) of their field-derived strains. The maximum RR relative to BZ was 9.0, which was found for a strain derived from Cry1A.105 + Cry2Ab corn from Lonoke, AR in 2019. Their analysis tends to underestimate the extent and magnitude of resistance because non-overlap of $95 \%$ FL is a conservative statistical test and our results show that susceptibility to Vip3Aa was lower for the BZ strain than for the other lab strains. Moreover, five of their six field-derived strains with significant resistance to Vip3Aa relative to BZ were started with $H$. zea from non-Vip3Aa host plants. Of the 29 field-derived strains they evaluated, the only one derived from a Vip3Aa plant came from cotton producing Cry1Ac + Cry1Fa + Vip3Aa in Grant, LA and was significantly resistant relative to BZ $(\mathrm{RR}=2.3)$.

In a related paper with the same senior author and bioassay methods as Niu et al. [22], Guo et al. [21] compared the $\mathrm{LC}_{50}$ value of Vip3Aa they recorded for BZ $\left(1.14 \mu \mathrm{g}\right.$ per $\mathrm{cm}^{2}$ diet; $95 \%$ FL $=0.58,1.69$ ) versus 11 strains derived in 2018 and 2019 from the Louisiana State University Agricultural Center (LSUAC) near Winnsboro, LA. Relative to BZ, 8 of their 11 field-derived strains had significantly lower $\mathrm{LC}_{50}$ values, and none had a significantly higher $\mathrm{LC}_{50}$ value. Even relative to the lower $\mathrm{LC}_{50}$ of BZ reported by Niu et al. [22] noted above, only 1 of the 11 strains had a significantly higher $L_{50}$ value. These results showed that the population studied by Guo et al. [21] was not resistant to Vip3Aa relative to BZ. These results also suggest that the resistance relative to BZ in 6 of the 29 field-derived strains reported by Niu et al. [22] reflects genetic variation among populations rather than the random experimental error that occurs in repeated tests of the same population as reported by Guo et al. [21]. Because Guo et al. [21] found only one live H. zea larva on 1200 ears of corn producing Cry1Ab + Vip3Aa and the only other corn in the plots they sampled was non-Bt corn, we infer that all or nearly all of the larvae used to start their 11 field-derived strains were collected from non-Bt corn.

Leite et al. [39] used diet overlay bioassays to assess baseline variation in $H$. zea susceptibility to Vip3Aa in Brazil before 2014 when Vip3Aa plants were not widely grown there. The mean $\mathrm{LC}_{50}$ was $0.13 \mu \mathrm{g}$ Vip3Aa per $\mathrm{cm}^{2}$ diet (range: $0.04-0.21$ ) for the six field-derived strains they tested. Although they did not test a lab strain, all of the $\mathrm{LC}_{50}$ values they reported for the six field-derived strains are significantly lower than the $\mathrm{LC}_{50}$ of BZ reported by Niu et al. [22].

Before Bt crops producing Vip3Aa were registered in the United States, Ali and Luttrell [40] also used diet bioassays to evaluate $H$. zea susceptibility to Vip3Aa. Based on results from experiments using the diet overlay bioassay methods followed in our study and the three other studies summarized above [21,22,39], they reported values for their lab strain LabZA of $0.10(0.08,0.13)$ for $\mathrm{LC}_{50}$ and $0.08(0.06,0.10)$ for $\mathrm{MIC}_{50}$ (both in $\mu \mathrm{g}$ Vip3Aa per $\mathrm{cm}^{2}$ diet; see Methods for details). Both of these values for LabZA are significantly lower than the $\mathrm{LC}_{50}$ of $\mathrm{BZ}$ of $0.40(0.30,0.51)$ reported by Niu et al. [22]. Based on diet incorporation bioassays (which differ from diet overlay bioassays), they reported that none of the field-derived strains derived in 2006 and 2007 from the field in Alabama, Arkansas, Louisiana, North Carolina, and Texas had an $\mathrm{LC}_{50}$ value significantly greater than LabZA tested in the same year. Despite the lower susceptibility of BZ than LabZA, the proportion of field-derived strains with significant resistance to Vip3Aa was significantly higher in the 2018-2019 study by Niu et al. [22] using BZ as the standard (6 of 29) than in the 2006-2007 baseline study [40] using LabZA as the standard (0 of 27) (Fisher's exact test; $p=0.02$ ). These results support the hypothesis that some of the field populations studied by Niu et al. [22] evolved resistance to Vip3Aa.

Although the results from our study and from Niu et al. [22] meet the criteria for early warning of resistance, the category of practical resistance has the following additional 
criteria: resistance reduces the efficacy of the Bt crop and has practical consequences for pest management, and more than $50 \%$ of individuals in a population are resistant [8]. To evaluate the potential for reduced efficacy, we compared the number of larvae per ear in Vip3Aa corn relative to related non-Bt corn reported in four previous studies where efficacy can be clearly attributed to Vip3Aa (Supplementary Table S7 and Methods). This ratio provides an estimate of the frequency of phenotypic resistance [41]. This ratio was 0.85 in a 2018 field trial in Snook, TX, where the diet bioassay results in the same year provide evidence of field-evolved resistance to Vip3Aa [19]. The ratio of 0.85 is 14 to 1062 times higher than the ratios from the other three studies: 0.06 for 2006 and 0.04 for 2007 in the baseline study of Burkness et al. [33], 0.06 and 0.01 for two field sites in Louisiana in 2018 [17], and 0.0008 for Winnsboro, LA in 2018 and 2019 [21] (One-sample $t$-test of $\log$-transformed data; $t=5.6 ; \mathrm{df}=4 ; p=0.005$ ). These ratios yield values of Vip3Aa efficacy of $15 \%$ for Snook in 2018 versus $94 \%$ to $99.9 \%$ for the other studies. Thus, in terms of decreasing the number of $H$. zea larvae per ear, the efficacy of Vip3Aa was reduced at Snook in 2018 relative to the other studies. However, the field data from Snook in 2018 also show 93\% efficacy of Vip3Aa in terms of reducing the damaged area per ear [19], suggesting minimal practical consequences.

In addition, based on survival at a concentration of $3 \mu \mathrm{g}$ Vip3Aa per $\mathrm{cm}^{2}$ diet as the criterion for resistance [36], none of the field-derived strains we tested met the criterion of having more than $50 \%$ resistant individuals. Niu et al. [22] reported that a strain derived in 2019 from Lonoke, AR had an $\mathrm{LC}_{50}$ of $3.60 \mu \mathrm{g}$ Vip3Aa per $\mathrm{cm}^{2}$ diet, which suggests it met this criterion, but they proposed a diagnostic concentration of 5 to $10 \mu \mathrm{g}$ Vip3Aa per $\mathrm{cm}^{2}$ diet. Leite et al. [39] suggested a diagnostic concentration of $6.4 \mu \mathrm{g}$ Vip3Aa per $\mathrm{cm}^{2}$ diet based on their data from Brazil. We favor the lower concentration used by Yang et al. [36] as a diagnostic concentration or lower concentrations, because they are likely to detect resistance sooner than the higher concentrations. More importantly, switching from measurement of $\mathrm{LC}_{50}$ values to survival at a diagnostic concentration can be more efficient for detecting resistance when it first evolves in the field [42].

In summary, we conclude that our results and related work provide strong evidence of field-evolved resistance that clearly meets the criteria for early warning of resistance but not practical resistance. Rather than focusing on the somewhat arbitrary distinction between these two categories, we emphasize our agreement with other scientists that action is needed now to preserve the efficacy of Vip3Aa against $H$. zea in the United States [20,43-45]. One option is to prohibit selling and planting field corn hybrids that produce Vip3Aa in the cotton-growing regions of the United States $[44,45]$. This would limit selection for resistance to Vip3Aa in corn, where $H$. zea is not a major economic pest, and thereby help to preserve its efficacy against $H$. zea in cotton where it is a major economic pest [44-46]. This approach was unanimously recommended by the Scientific Advisory Panel convened by the US EPA in 2018 to address lepidopteran resistance to Bt crops [44]. It is also supported by the National Cotton States Arthropod Pest Management Working Group and by 36 public sector entomologists who participate in Multistate Research Project NC246: Ecology and Management of Arthropods in Corn [45]. The evidence reported here and related data highlight the urgency to implement these recommendations to sustain the efficacy of Vip3Aa against $H$. zea.

\section{Materials and Methods}

\subsection{Strains of H. zea}

We tested three lab strains (BZ, SIMRU, and TM) and 71 strains of H. zea derived from the field in AR, LA, MS, TN, and TX during 2016 to 2020. Strains were reared at LSU, TAMU, and SIMRU as described previously, with larvae reared on diet without Bt toxins or other insecticides [38]. We obtained the BZ strain (called CBW-BZ-SS in [19]) from Benzon Research Inc., Carlisle, PA. The TM strain (called SS in [36]) was started from more than 150 larvae collected from non-Bt corn in May 2016 at the LSUAC near Winnsboro, LA. The SIMRU strain has been maintained in the lab since 1971 [18]. 
To start field-derived strains, third to fifth instar larvae of $H$. zea were collected from Bt and non-Bt host plants in the field (Tables 1-3). The Bt host plants include Bt corn: Intrasect, Obsession sweet corn, Leptra, SmartStax (STX), VT DoublePRO (VT2P), and VT TriplePro (VT3P); and Bt cotton: Bollgard II (BG2), Bollgard 3 (BG3), TwinLink, Widestrike (WS), and Widestrike3 (WS3). The non-Bt host plants include corn, cotton, crimson clover (Trifolium incarnatum), grain sorghum (Sorghum bicolor), and soybean (Glycine max). The field-collected larvae were put in $30 \mathrm{~mL}$ plastic cups (Solo ${ }^{\circledR}$ Mason, MI) containing Stonefly Heliothis diet (Ward's Natural Science, Rochester, NY). The cups were put in insulated boxes containing frozen blue ice and other packing materials, then sent via overnight delivery to LSU, TAMU or SIMRU where larvae were transferred one per cup into $30 \mathrm{~mL}$ cups containing fresh diet. To synchronize development of the field-collected larvae, they were sorted by instar and reared at different temperatures to accelerate the growth of earlier instars relative to later instars until all larvae were at the same developmental stage. We put pupae in $20 \mathrm{~L}$ mesh cages (Seville Classics Inc., Torrance, CA, USA) containing 200 g vermiculite (Sun Gro, Pine Bluff, AR, USA) and a 10\% honey-water solution to feed moths that emerged. Cages were maintained at $26 \pm 1{ }^{\circ} \mathrm{C}, \sim 60 \%$ relative humidity, and $16 \mathrm{~h}$ light: $8 \mathrm{~h}$ dark.

\subsection{ELISA Tests for Vip3Aa in Putative Vip3Aa Plants}

To check for Vip3Aa in putative Vip3Aa corn and cotton plants from which insects were collected at five field sites in 2018 and 2019 (Tables 2 and 3), we used ELISA tests according to the manufacturer's instructions (EnviroLogix, Quantiplate ${ }^{\mathrm{TM}}$ kits, Portland, $\mathrm{ME}$ ). From each of the five sites, we tested three to five plants expected to produce Vip3Aa and a similar number that were not expected to produce Vip3Aa. All plants tested that were expected to produce Vip3Aa yielded positive results in the ELISA tests, confirming the presence of Vip3Aa. No Vip3Aa was detected in the plants that were not expected to produce Vip3Aa.

\subsection{Diet Overlay Bioassays}

We conducted 80 diet overlay bioassays to determine the susceptibility to Vip3Aa of 71 field-derived strains and three lab strains (total of 9 bioassays: BZ tested six times, TM tested in 2018 and 2019, and SIMRU tested in 2016). The 2016 bioassays were performed at the LSU Department of Entomology. The other bioassays were performed at TAMU, except for 11 conducted at SIMRU in 2019 for BZ and 10 field-derived strains (Table 3). For 68 of the 71 field-derived strains, we tested the first-generation $\left(\mathrm{F}_{1}\right)$ progeny of the field-collected insects. Because of insufficient numbers of $F_{1}$, we tested the $F_{2}$ progeny for three strains from Bt cotton (from Cry1Ac + Cry2Ab cotton from Alexandria, LA in 2016 and Wharton, TX in 2018; and from Cry1Ab + Cry2Ae cotton from Stoneville, MS in 2019 and tested at SIMRU).

To test each strain, we used concentrations of $0,0.01,0.0316,0.1,0.316,1.0$, and $3.16 \mu \mathrm{g}$ Vip3Aa per $\mathrm{cm}^{2}$ diet. Each combination of insect strain by Vip3Aa concentration was replicated four times with 16 to 32 larvae per replicate. We put $0.8 \mathrm{~mL}$ of liquid $H$. zea diet (Southland Products Inc., Lake Village, AR, USA) per well in 128-well bioassay trays (C-D International, Pitman, NJ, USA). After the diet cooled and solidified, $40 \mu \mathrm{L}$ of a suspension containing an appropriate concentration of Vip3Aa in $0.1 \%$ Triton-X100 was overlaid on the diet surface of each well and allowed to dry. We put one neonate $(<24 \mathrm{~h}$ old) on the diet surface of each well and covered all wells with vented lids (C-D International, Pitman, NJ, USA). We put the bioassay trays in an environmental chamber at $26 \pm 1{ }^{\circ} \mathrm{C}, 50 \%$ relative humidity, and $14 \mathrm{~h}$ light: $10 \mathrm{~h}$ dark. After 7 days, we recorded the number of dead larvae and the instar of live larvae.

\subsection{Vip3Aa}

We used Vip3Aa19 in 2016 and 2017, Vip3Aa51 in 2018, and Vip3Aa39 in 2019 and 2020. Vip3Aa19 was provided by Syngenta and Vip3Aa51 by BASF (both at Research Triangle Park, NC, USA). Juan Luis Jurat-Fuentes, University of Tennessee, provided Vip3Aa39. 
The amino acid sequences of Vip3Aa39 and Vip3Aa51 are identical and 97.1\% similar to Vip3Aa19 [47], which is produced by Bt cotton. Relative to Vip3Aa20 produced by Bt corn, the amino acid sequence similarity is $99.9 \%$ for Vip3Aa19 and $97.1 \%$ for Vip3Aa39 and Vip3Aa51 [47]. Because the amino acid sequence similarity among these toxins is $97.1 \%$ to $100 \%$, we refer to all of them as Vip3Aa. However, rather than assuming these toxins had identical potency against $H$. zea, we recognize that potency could have varied among them or even across years or between labs for the same toxin. Thus, we emphasize comparisons between strains that were tested with the same toxin in the same year and the same lab. See Results section for details of how we calculated RRs and made comparisons between strains.

\subsection{Data Analysis}

\subsubsection{Diet Bioassay Data}

We used probit analysis [48] to calculate the concentration of Vip3Aa causing 50\% larval mortality ( $\mathrm{LC}_{50}$ ) and the corresponding 95\% fiducial limits (FL) for each strain. Larval mortality was based on the number of dead larvae and live first instars and was adjusted for control mortality before the data were entered for probit analysis [38]. As done here, four previous studies of $H$. zea responses to Vip3Aa use the term $\mathrm{LC}_{50}$ to refer to the metric based on the number of dead larvae and live first instars [21,22,31,39]. Welch et al. [32] call this $\mathrm{EC}_{50}$. Ali and Luttrell [40] call it $\mathrm{MIC}_{50}$ and use the term $\mathrm{LC}_{50}$ for larval mortality only (not including live first instars). Three of the 80 values of the $\mathrm{LC}_{50}$ of Vip3Aa reported in Tables 1-3 were reported previously: two for strains derived in Snook, TX in 2018; one from corn producing Cry1 Ab + Cry1Fa + Vip3Aa; one from corn producing Cry1A.105 + Cry2Ab (called CEW-TX-Leptra-2018 and CEW-TX-VGT3P-2018, respectively, in [19]; and one for the TM lab strain tested in 2019 (called SS in [36]).

We considered two values of $\mathrm{LC}_{50}$ significantly different if their $95 \%$ FL did not overlap, which is a conservative criterion $[49,50]$. In addition to such pairwise comparisons, we conducted a regression analysis and $t$-tests using log-transformed values of RRs.

\subsubsection{Efficacy of Vip3Aa Corn}

We calculated the number of larvae per ear in $\mathrm{Bt}$ corn relative to comparable non-Bt corn using data from four previous field studies $[17,19,21,33]$ from which we can reasonably infer that Vip3Aa was the sole or primary Bt toxin reducing the number of $H$. zea larvae per ear (Supplementary Table S7). From Burkness et al. [33], the data we used for Bt corn are for hybrids producing only Vip3Aa. In Yang et al. [19] and Kaur et al. [17], Cry1Ab + Cry1Fa corn did not have fewer larvae per ear than related non-Bt corn, so the reported efficacy of Cry1Ab + Cry1Fa + Vip3Aa corn can be attributed to Vip3Aa. Guo et al. [21] reported high levels of resistance to Cry1 $\mathrm{Ab}$, so the efficacy they reported for Cry1 $\mathrm{Ab}+$ Vip3Aa corn can be attributed primarily or entirely to Vip3Aa.

We used a one-sample $t$-test of the log-transformed data to assess the difference between the results from Snook, TX in 2018 and the other previous results in the ratio of larvae per ear in Bt corn relative to non-Bt corn. We quantified the efficacy of Bt corn in terms of reducing the number of larvae per ear as 100\% multiplied by (1 - [LBt/LNon-Bt], where LBt and LNon-Bt are the number of larvae per ear for Bt and comparable non-Bt corn, respectively [8]. Thus, efficacy is $0 \%$ when LBt equals LNon-Bt, and $100 \%$ when LBt equals 0 .

Dively et al. [20] reported mean ratios from 19 to 27 trials per time period for the number of larvae per ear in sweet corn producing Cry1 Ab + Vip3Aa relative to its isoline non-Bt corn, which were 0.006 in 2007-2014, 0.008 in 2017, 0.024 in 2018, and 0.014 in 2019. Because these ratios may be affected by variation in efficacy of Cry1 $\mathrm{Ab}$ across years and locations, we did not include them in the analysis reported in the Discussion. However, additional analyses that include either all of the data from Dively et al. [20] or just their data from 2017 to 2019 when we expect the efficacy of Cry1Ab was limited, confirm the conclusion reported in the Discussion that the ratio of larvae per ear in Vip3Aa corn relative 
to non-Bt corn for Snook, TX in 2018 was significantly higher than the previously reported ratios (One-sample $t$-tests of log-transformed data; $p<0.0001$ for both additional analyses).

\subsection{Population Genetic Modeling}

We used a previously described deterministic population genetic model of $H$. zea [51]. We assumed resistance was controlled by a single locus with a recessive allele for resistance $[36,38]$ and another allele for susceptibility. The initial frequency of the resistance allele was set at 0.0065, as estimated for 2019 for $H$. zea in Texas [38]. The dominance parameter $h$ was set to zero, indicating completely recessive resistance, as empirically determined [36]. We assumed the fitness of resistant homozygotes was 1.0 for individuals that developed as larvae on plants with or without Vip3Aa. This represents complete resistance to Vip3Aa and no fitness cost associated with resistance on non-Vip3Aa plants. Non-Vip3Aa plant refuges accounted for $10 \%$ of all host plants. To predict the resistance allele frequency in 2020, we used the model to simulate one year. The assumptions we evaluated are pessimistic, because the expected resistance allele frequency would be lower in 2020 if the resistant homozygotes were not completely resistant to Vip3Aa plants, the resistance carried a fitness cost, or non-Vip3Aa plants provided a refuge accounting for more than $10 \%$ of all host plants.

Supplementary Materials: The following are available online at https:/ /www.mdpi.com/article/10.3 390/toxins13090618/s1, Supplementary Methods. Adoption of Vip3Aa corn and cotton. Tables S1-S6. Adoption of Vip3Aa corn and cotton. Table S7. Larvae per ear in Vip3Aa corn relative to comparable non-Bt corn in four previous field studies. Figure S1. Map of field sites for monitoring resistance of H. zea to Vip3Aa. References $[25,26,52-57]$ are cited in the supplementary materials.

Author Contributions: F.Y., D.L.K., N.S.L. and B.E.T. conceived the study; F.Y., N.S.L. and J.C.S.G. conducted lab bioassays; B.E.T. conducted modeling; F.Y., D.L.K., N.S.L. and B.E.T. analyzed the data; B.E.T. wrote the manuscript; all authors reviewed the manuscript and provided input. All authors have read and agreed to the published version of the manuscript.

Funding: This work was supported by grants from the USDA National Institute of Food and Agriculture (Biotechnology Risk Assessment Research Grants Program 2017-33522-27090/project accession no. 1013740 and Agriculture and Food Research Initiative 2020-67013-31924) and by the Cotton Technical Subcommittee of the Agricultural Biotechnology Stewardship Technical Committee (ABSTC).

Institutional Review Board Statement: Not applicable.

Informed Consent Statement: Not applicable.

Data Availability Statement: The data are available in the article and in the Supplementary Materials.

Acknowledgments: We thank BASF, Syngenta, and Juan Luis Jurat-Fuentes, University of Tennessee, for providing Vip3Aa. We also thank the Cotton Subcommittee of the ABSTC for helping us obtain Vip3Aa from BASF and Syngenta. For providing us with $H$. zea larvae they collected from the field, we are grateful to Jeff Gore, Angus Catchot, Don Cook, and Whitney Crow, Mississippi State University; Gus Lorenz and Ben Thrash, University of Arkansas; Scott Stewart, University of Tennessee; Sebe Brown and Tyler Towles, Louisiana State University; and Kate Crumley, Danielle Sekula, Stephen Biles, John David Gonzales, Tyler Mays, Pat Porter, Suhas Vyavhare, and Danielle Sekula from Texas A\&M AgriLife Extension Service. We are grateful to ABSTC for graciously providing sales data for Vip3Aa corn and cotton. We also thank Yves Carrière and ABSTC members for thoughtful comments and Neil Crickmore for assistance with comparing Vip3Aa amino acid sequences.

Conflicts of Interest: This work was funded in part by the Cotton Subcommittee of the ABSTC, which is a consortium of agricultural biotechnology companies. 


\section{References}

1. Hutchison, W.D.; Burkness, E.C.; Mitchell, P.D.; Moon, R.D.; Leslie, T.W.; Fleischer, S.J.; Abrahamson, M.; Hamilton, K.L.; Steffey, K.L.; Gray, M.E.; et al. Areawide suppression of European corn borer with Bt maize reaps savings to non-Bt maize growers. Science 2010, 330, 222-225. [CrossRef]

2. Gould, F.; Amasino, R.M.; Brossard, D.; Buell, C.R.; Dixon, R.A.; Falck-Zepeda, J.B.; Gallo, M.A.; Giller, K.; Glenna, L.; Grin, T.S.; et al. Genetically Engineered Crops: Experiences and Prospects; National Academies of Sciences, Engineering and Medicine; National Academies Press: Washington, DC, USA, 2016.

3. Dively, G.P.; Venugopal, P.D.; Bean, D.; Whalen, J.; Holmstrom, K.; Kuhar, T.P.; Doughty, H.B.; Patton, T.; Cissel, W.; Hutchison, W.D. Regional pest suppression associated with widespread Bt maize adoption benefits vegetable growers. Proc. Natl. Acad. Sci. USA 2018, 115, 3320-3325. [CrossRef]

4. Tabashnik, B.E.; Liesner, L.R.; Ellsworth, P.C.; Unnithan, G.C.; Fabrick, J.A.; Naranjo, S.E.; Li, X.; Dennehy, T.J.; Antilla, L.; Staten, R.T.; et al. Transgenic cotton and sterile insect releases synergize eradication of pink bollworm a century after it invaded the United States. Proc. Natl. Acad. Sci. USA 2021, 118, e2019115118. [CrossRef] [PubMed]

5. International Service for the Acquisition of Agri-Biotech Applications. Global Status of Commercialized Biotech/GM Crops in 2019: Biotech Crops Drive Socio-Economic Development and Sustainable Environment in the New Frontier; ISAAA Brief No. 55; International Service for the Acquisition of Agri-Biotech Applications: Ithaca, NY, USA, 2019.

6. Tabashnik, B.E.; Carrière, Y. Global patterns of resistance to Bt crops highlighting pink bollworm in the United States, China, and India. J. Econ. Entomol. 2019, 112, 2513-2523. [CrossRef]

7. Tabashnik, B.E.; Carrière, Y. Surge in insect resistance to transgenic crops and prospects for sustainability. Nature Biotech. 2017, 35, 926-935. [CrossRef] [PubMed]

8. Tabashnik, B.E.; Mota-Sanchez, D.; Whalon, M.E.; Hollingworth, R.M.; Carrière, Y. Defining terms for proactive management of resistance to Bt crops and pesticides. J. Econ. Entomol. 2014, 107, 496-507. [CrossRef]

9. Calles-Torrez, V.; Knodel, J.J.; Boetel, M.A.; French, B.W.; Fuller, B.W.; Ransom, J.K. Field-evolved resistance of northern and western corn rootworm (Coleoptera: Chrysomelidae) populations to corn hybrids expressing single and pyramided Cry3Bb1 and Cry34/35Ab1 Bt proteins in North Dakota. J. Econ. Entomol. 2019, 112, 1875-1886. [CrossRef] [PubMed]

10. Smith, J.L.; Farhan, Y.; Schaafsma, A.W. Practical resistance of Ostrinia nubilalis (Lepidoptera: Crambidae) to Cry1F Bacillus thuringiensis maize discovered in Nova Scotia, Canada. Sci. Rep. 2019, 9, 18247. [CrossRef]

11. Luttrell, R.G.; Jackson, R.E. Helicoverpa zea and Bt cotton in the United States. GM Crops Food 2012, 3, 213-227. [CrossRef]

12. Luttrell, R.G.; Ali, I.; Allen, K.C.; Young, S.Y., III; Szalanski, A.; Williams, K.; Lorenz, G.; Parker, C.D., Jr.; Blanco, C. Resistance to Bt in Arkansas populations of cotton bollworm. In Proceedings of the 2004 Beltwide Cotton Conferences, San Antonio, TX, USA, 5-9 January 2004; Richter, D.A., Ed.; National Cotton Council of America: Memphis, TN, USA, 2004; pp. $1373-1383$.

13. Tabashnik, B.E.; Gassmann, A.J.; Crowder, D.W.; Carrière, Y. Field-evolved resistance to Bt toxins. Nat. Biotech. 2008, 26, 1074-1076. [CrossRef]

14. Dively, G.P.; Venugopal, P.D.; Finkenbinder, C. Field-evolved resistance in corn earworm to Cry proteins expressed by transgenic sweet corn. PLoS ONE 2016, 11, e0169115. [CrossRef]

15. Reisig, D.D.; Huseth, A.S.; Bacheler, J.S.; Aghaee, M.A.; Braswell, L.; Burrack, H.J.; Flanders, K.; Greene, J.K.; Herbert, D.A.; Jacobson, A. Long-term empirical and observational evidence of practical Helicoverpa zea resistance to cotton with pyramided Bt toxins. J. Econ. Entomol. 2018, 111, 1824-1833. [CrossRef]

16. Bilbo, T.R.; Reay-Jones, F.P.; Reisig, D.D.; Greene, J.K. Susceptibility of corn earworm (Lepidoptera: Noctuidae) to Cry1A.105 and Cry2Ab2 in North and South Carolina. J. Econ. Entomol. 2019, 112, 1845-1857. [CrossRef]

17. Kaur, G.; Guo, J.; Brown, S.; Head, G.P.; Price, P.A.; Paula-Moraes, S.; Ni, X.; Dimase, M.; Huang, F. Field-evolved resistance of Helicoverpa zea (Boddie) to transgenic maize expressing pyramided Cry1A.105/Cry2Ab2 proteins in northeast Louisiana, the United States. J. Invertebr. Pathol. 2019, 163, 11-20. [CrossRef]

18. Little, N.S.; Elkins, B.H.; Mullen, R.M.; Perera, O.P.; Parys, K.A.; Allen, K.C.; Boykin, D.L. Differences between two populations of bollworm, Helicoverpa zea (Lepidoptera: Noctuidae), with variable measurements of laboratory susceptibilities to Bt toxins exposed to non-Bt and Bt cottons in large field cages. PLoS ONE 2019, 14, e212567. [CrossRef]

19. Yang, F.; González, J.C.; Williams, J.; Cook, D.C.; Gilreath, R.T.; Kerns, D.L. Occurrence and ear damage of Helicoverpa zea on transgenic Bacillus thuringiensis maize in the field in Texas, US and its susceptibility to Vip3A protein. Toxins 2019, 11, 102. [CrossRef] [PubMed]

20. Dively, G.P.; Kuhar, T.P.; Taylor, S.; Doughty, H.B.; Holmstrom, K.; Gilrein, D.; Nault, B.A.; Ingerson-Mahar, J.; Whalen, J.; Reisig, D.; et al. Sweet corn sentinel monitoring for lepidopteran field-evolved resistance to Bt toxins. J. Econ. Entomol. 2021, 114, 307-319. [CrossRef] [PubMed]

21. Guo, J.; Oyediran, I.; Rice, M.E.; Brown, S.; Dimase, M.; Lin, S.; Walker, W.; Yu, W.; Niu, Y.; Huang, F. Seed blends of pyramided Cry/Vip maize reduce Helicoverpa zea populations from refuge ears. J. Pest. Sci. 2021, 94, 959-968. [CrossRef]

22. Niu, Y.; Oyediran, I.; Yu, W.; Lin, S.; Dimase, M.; Brown, S.; Reay-Jones, F.P.F.; Cook, D.; Reisig, D.; Thrash, B.; et al. Populations of Helicoverpa zea (Boddie) in the southeastern United States are commonly resistant to Cry1Ab, but still susceptible to Vip3Aa20 expressed in MIR 162 corn. Toxins 2021, 13, 63. [CrossRef] [PubMed]

23. Reay-Jones, F.P.F. Pest status and management of corn earworm (Lepidoptera: Noctuidae) in field corn in the United States. J. Integr. Pest. Manag. 2019, 10, 1-9. [CrossRef] 
24. Tabashnik, B.E.; Van Rensburg, J.B.J.; Carrière, Y. Field-evolved insect resistance to Bt crops: Definition, theory, and data. J. Econ. Entomol. 2009, 102, 2011-2025. [CrossRef]

25. Yu, J.; Hennessy, D.A.; Wu, F. The impact of Bt corn on aflatoxin-related insurance claims in the United States. Sci. Rep. 2020, 10, 10046. [CrossRef]

26. US Department of Agriculture; Agricultural Marketing Service. Cotton Varieties Planted 2020 Crop. Available online: https: / / www.ams.usda.gov / mnreports / cnavar.pdf (accessed on 15 May 2021).

27. Byrne, M.J.; Iadanza, M.G.; Perez, M.A.; Maskell, D.P.; George, R.M.; Hesketh, E.L.; Beales, P.A.; Zack, M.D.; Berry, C.; Thompson, R.F. Cryo-EM structures of an insecticidal Bt toxin reveal its mechanism of action on the membrane. Nature Comm. $2021,12,279$. [CrossRef] [PubMed]

28. Syed, T.; Askari, M.; Meng, Z.; Li, Y.; Abid, M.A.; Wei, Y.; Guo, S.; Lian, C.; Zhang, R. Current insights on vegetative insecticidal proteins (Vip) as next generation pest killers. Toxins 2020, 12, 522. [CrossRef] [PubMed]

29. Chakroun, M.; Banyuls, N.; Bel, Y.; Escriche, B.; Ferré, J. Bacterial vegetative insecticidal proteins (Vip) from entomopathogenic bacteria. Microbiol. Mol. Biol. Rev. 2016, 80, 329-350. [CrossRef] [PubMed]

30. Tabashnik, B.E.; Carrière, Y. Evaluating cross-resistance between Vip and Cry toxins of Bacillus thuringiensis. J. Econ. Entomol. 2020, 113, 553-561. [CrossRef] [PubMed]

31. Anilkumar, K.J.; Rodrigo-Simón, A.; Ferré, J.; Pusztai-Carey, M.; Sivasupramaniam, S.; Moar, W.J. Production and characterization of Bacillus thuringiensis Cry1Ac-resistant cotton bollworm Helicoverpa zea (Boddie). Appl. Environ. Microbiol. 2008, 74, 462-469. [CrossRef] [PubMed]

32. Welch, K.L.; Unnithan, G.C.; Degain, B.A.; Wei, J.; Zhang, J.; Li, X.; Tabashnik, B.E.; Carrière, Y. Cross-resistance to toxins used in pyramided Bt crops and resistance to Bt sprays in Helicoverpa zea. J. Invertebr. Pathol. 2015, 132, 149-156. [CrossRef] [PubMed]

33. Burkness, E.C.; Dively, G.; Patton, T.; Morey, A.C.; Hutchison, W.D. Novel Vip3A Bacillus thuringiensis (Bt) maize approaches highdose efficacy against Helicoverpa zea (Lepidoptera: Noctuidae) under field conditions: Implications for resistance management. GM Crops 2010, 1, 337-343. [CrossRef]

34. Yang, F.; Kerns, D.L.; Leonard, B.R.; Oyediran, I.; Burd, T.; Niu, Y.; Huang, F. Performance of Agrisure ${ }^{\circledR}$ Viptera ${ }^{\mathrm{TM}} 3111$ corn against Helicoverpa zea (Lepidoptera: Noctuidae) in seed mixed plantings. Crop. Prot. 2015, 69, 77-82. [CrossRef]

35. Brown, S.; Walker, W.; Cole, C. Efficacy and field performance of Bt cotton in Louisiana. In Proceedings of the 2019 Beltwide Cotton Conferences, New Orleans, LA, USA, 8-10 January 2019; National Cotton Council of America: Memphis, TN, USA, 2019; pp. 477-480.

36. Yang, F.; González, J.C.S.; Sword, G.A.; Kerns, D.L. Genetic basis of resistance to the Vip3Aa Bt protein in Helicoverpa zea. Pest. Manag. Sci. 2021. [CrossRef] [PubMed]

37. Falconer, D.S. Introduction to Quantitative Genetics, 3rd ed.; John Wiley \& Sons: New York, NY, USA, 1989.

38. Yang, F.; González, J.C.S.; Little, N.; Reisig, D.; Payne, G.; Dos Santos, R.F.; Jurat-Fuentes, J.L.; Kurtz, R.; Kerns, D.L. First documentation of major Vip3Aa resistance alleles in field populations of Helicoverpa zea (Boddie) (Lepidoptera: Noctuidae) in Texas, USA. Sci. Rep. 2020, 10, 5867. [CrossRef]

39. Leite, N.A.; Pereira, R.M.; Durigan, M.R.; Amado, D.; Fatoretto, J.; Medeiros, F.C.L.; Omoto, C. Susceptibility of Brazilian populations of Helicoverpa armigera and Helicoverpa zea (Lepidoptera: Noctuidae) to Vip3Aa20. J. Econ. Entomol. 2018, 111, 399-404. [CrossRef]

40. Ali, M.I.; Luttrell, R.G. Susceptibility of Helicoverpa zea and Heliothis virescens (Lepidoptera: Noctuidae) to Vip3A insecticidal toxin expressed in VipCot ${ }^{\mathrm{TM}}$ cotton. J. Invertebr. Pathol. 2011, 108, 76-84. [CrossRef] [PubMed]

41. Venette, R.C.; Hutchison, W.D.; Andow, D.A. An in-field screen for early detection and monitoring of insect resistance to Bacillus thuringiensis in transgenic crops. J. Econ. Entomol. 2000, 93, 1055-1064. [CrossRef] [PubMed]

42. Roush, R.T.; Miller, G.L. Considerations for design of insecticide resistance monitoring programs. J. Econ. Entomol. 1986, 79, 293-298. [CrossRef]

43. Reisig, D.D.; Kurtz, R. Bt resistance implications for Helicoverpa zea (Lepidoptera: Noctuidae) insecticide resistance management in the United States. Environ. Entomol. 2018, 47, 1357-1364. [CrossRef]

44. US Environmental Protection Agency. Resistance in Lepidopteran Pests to Bacillus thuringiensis (Bt) Plant Incorporated Protectants (PIPs) in the United States; July 2018 SAP Meeting Minutes. Available online: https:/ / www.regulations.gov/document?D=EPAHQ-OPP-2017-0617-0078 (accessed on 15 June 2021).

45. Reisig, D.D.; Dively, G.; Gore, J.; DiFonzo, C.; Farhan, Y.; Smith, J. Response to the EPA Draft Proposal to Address Resistance Risks to Lepidopteran Pests of Bt Following the July 2018 FIFRA Scientific Advisory Panel Recommendation Memorandum. Available online: https:/ / www.regulations.gov/comment/EPA-HQ-OPP-2019-0682-0031 (accessed on 15 June 2021).

46. Caprio, M.A.; Kurtz, R.; Catchot, A.; Kerns, D.; Reisig, D.; Gore, J.; Reay-Jones, F.P.F. The corn-cotton agroecosystem in the mid-southern United States: What insecticidal event pyramids should be used in each crop to extend Vip3A durability. J. Econ. Entomol. 2019, 112, 2894-2906. [CrossRef]

47. Bacterial Pesticidal Protein Resource Center. Available online: https://camtech-bpp.ifas.ufl.edu/bestmatchfinder_database/ (accessed on 10 June 2021).

48. SAS Institute. SAS/STAT 9.3 User's Guide; SAS Institute Inc.: Cary, NC, USA, 2011.

49. Tabashnik, B.E.; Cushing, N.L.; Johnson, M.W. Diamondback moth (Lepidoptera: Plutellidae) resistance to insecticides in Hawaii: Intra-island variation and cross-resistance. J. Econ. Entomol. 1987, 80, 1091-1099. [CrossRef] 
50. Payton, M.E.; Greenstone, M.H.; Schenker, N. Overlapping confidence intervals or standard error intervals: What do they mean in terms of statistical significance? J. Insect Sci. 2003, 3, 34-40. [CrossRef] [PubMed]

51. Brévault, T.; Heuberger, S.; Zhang, M.; Ellers-Kirk, C.; Ni, X.; Masson, L.; Li, X.; Tabashnik, B.E.; Carrière, Y. Potential shortfall of pyramided Bt cotton for resistance management. Proc. Natl. Acad. Sci. USA 2013, 110, 5806-5811. [CrossRef] [PubMed]

52. Schnell, R.; Horn, K.; Blair, E.; Murray, S. 2020 Texas Corn Performance Variety Trials. Texas A\&M AgriLife. SCS-2020-11. 2020. Available online: https:/ / varietytesting.tamu.edu/files/corn/2020/2020-CORN-PUBLICATION.PDF (accessed on 23 August 2021).

53. Saavoss, M.; Capehart, T.; McBride, W.; Effland, A. Trends in Production Practices and Costs of the U.S. Corn Sector, ERR-2 USDA, Economic Research Service. 2021. Available online: https:/ / www.ers.usda.gov/webdocs/publications/101722/err-294.pdf?v= 2087.7 (accessed on 23 August 2021).

54. Robinson, E. Calculator Compares Cotton Seed Costs. 2003. FarmProgress. Available online: https://www.farmprogress.com/ calculator-compares-cotton-seed-costs (accessed on 23 August 2021).

55. U.S. Environmental Protection Agency (EPA). Acres Planted per Day and Seeding Rates of Crops Grown in the United States. 2010. Available online: https:/ / www.epa.gov/sites/default/files/2018-01/documents/seeding-rates-and-acres-planted-perday-revised-final-030111.pdf (accessed on 23 August 2021).

56. USDA National Agricultural Statistics Service (NASS). Crop Production. 2020. Available online: https://www.nass.usda.gov / Publications/Todays_Reports/reports/cropan20.pdf (accessed on 23 August 2021).

57. USDA National Agricultural Statistics Service (NASS). Acreage. 2021. Available online: https://www.nass.usda.gov/ Publications/Todays_Reports/reports/acrg0621.pdf (accessed on 23 August 2021). 